\title{
Examining Statistical Distributions and Statistical Behavior of Stem Tapers of Fagus Sylvatica in Municipal Forest of Naoussa
}

\author{
Messaritakis Spyridon, Aristotle University of Thessaloniki, Department of Forestry, Thessaloniki, Greece
}

\begin{abstract}
The aim of the present research is the study of the statistical behavior of ninety-three tapers. Tapers are classified into three categories depending on whether they use measured diameters at relative or absolute heights in the tree trunk. In each taper, measures of central tendency, measures of dispersion and a measure of skewness were examined. Each taper was examined if it fits normal distribution or not. It emerged that in the first category all tapers approached the normal distribution. In the second category, eight of the ten tapers are satisfactorily reaching the normal distribution, while in the third category thirty-seven out of seventy-eight are satisfactorily reaching the normal distribution. Data used in the research were collected in the Municipal Forest of Naoussa from 300 trees of Fagus sylvatica using random sampling.
\end{abstract}

\section{KEYWORDS}

Descriptive Statistics, Distributions Forest Biometry, Naoussa, Stem Taper, Stem Volume

\section{INTRODUCTION}

Stem is a dynamic part of tree. Stem affects total growth of tree, the economic value and the status of the tree in a cluster. Taper is the term used to describe the decrease in tree stem diameter with increasing height. Technically it is a rate, with units of centimeter / meter or inches / feet. According to Grey (1956) taper is the rate of change in diameter in relation to the increase in height along the tree stem. Taper can be used in taper equations as a variable in order to estimate volume of a tree or diameter of a tree stem at any height (Goodwin, 2009; Ikonen et al., 2006; Larsen, 2017; West, 2009).

A taper is affected by many factors such as species, genotype, age, silviculture treatments, stand density, weather conditions, especially wind, the size of live crown and the distribution of the live crown along the stem (Larson, 1963). Major stand treatments that alter stand density, such as thinning, pruning, and fertilization are expected to affect taper through subsequent changes in both crown size and crown class (Muhairwe et al., 1993). For example, thinning reduces stand density and allows individual trees more space to expand their crowns. In heavily thinned stands trees will grow like 
open - grown trees and will have big crowns and look more conical in shape, showing high taper particularly for the trees base (Thomson \& Barclay, 1984) Also, a tree in a windy area is more tapered than a tree in a non-windy area. Anuchin (1970) mentioned that taper varies in different portions of the stem, being fairly large near the butt on account of the root swelling, diminishing toward the middle and increasing again toward the top. According to Assmann (1970) stem taper is a complex trait that varies substantially depending on genetic factors (within and among-species), environmental factors (inter alia soil type, hydrology, altitude and climate), forest management practices and interactions between all of these factors.

The difference between the diameters of two cross sections separated by a distance of 1 meter along the stem is absolute taper. In this research the mean taper was used in all taper calculations. Mean taper is equal to the difference between the large diameter $d_{1}$ and small diameter $d_{2}$ divided by their distance $L$ (Equation 1):

$\alpha=\frac{d_{1}-d_{2}}{L}$

Anuchin (1970) made detailed measurements of over 4,000 logs and established a direct relationship between the mean taper and the log diameter. Prodan (1965) calculated mean taper to estimate the total stem volume and also used the following formulas for taper:

$$
\begin{aligned}
& \alpha=\frac{d_{0.1 h}-d_{0.5 h}}{0.4 h} \\
& \alpha=\frac{d_{1.3}}{h} \\
& \alpha=\frac{d_{1.3}-d_{0.5 h}}{0.5 h-1.3}
\end{aligned}
$$

where $d_{1.3}$ is the stem diameter at 1.3 meters from the ground, $d_{0.1 h}$ is the stem diameter at 0.1 of the total high of the tree, $d_{0.5 h}$ is the stem diameter at 0.5 of the total high and $h$ is the total height of the tree.

The knowledge of taper will improve the understanding of species in several ways (Maraseni et al., 2007). It will help to improve estimation of log volume, which could be used for estimation of stem volume. Furthermore, it will help to estimate the amount of sawn timber, as for a given volume severely tapered logs will provide less sawn timber than less tapered logs. Also, by knowing the taper, the forest managers can have better information about the growing condition of the trees.

According to Van Laar \& Akca (2007) knowledge of taper is important in order forest managers require information about the diameter of the bole at fixed distances from the base of the tree, for example, to predict the recovery of saw logs of different diameter and length or the yield of poles of varying dimensions, for trees of different dbh and height.

According to Kozak (1988) by knowing tapers, taper functions can be used. Kozak (1988) mentions that taper functions are known to provide estimates of over and under bark diameter in every high along the stem, to estimate the total stem volume, to estimate a part of the stem volume, and to estimate the high where is a specific diameter.

Understanding stem form and its dynamics over time is an important tool for identifying the appropriate moment in which thinning or final felling should be carried out in forest plantations. 
This is because stem form defines a forest's assortment and its economic value. One of the aims of this research is to calculate and compare many of tapers and examine their statistical behavior, if they fit to the Normal distribution, a very common continuous distribution, providing information to forest managers to control and review the effectiveness of management and silvicultural treatments. According to Podlaski \& Zasada (2008), the knowledge of theoretical distributions describing data from mixed forests of abies and fagus would be advantageous in dendrometry, silviculture, forest management, and ecology.

\section{MATERIAL AND METHODS}

The data used in this study were collected from Municipal Forest of Naoussa and for the species of Fagus sylvatica. Trees were randomly selected. Trees possessing multiple stems, broken tops, large knots, stem deformations, obvious cankers, or crooked boles were not included in the sample. The forest is in north and northeast slopes of Vermio Mountain from height 380 meters to 2,027 meters having main species trees of Fagus sylvatica, Castanea sativa, and Pinus nigra. The species of Fagus sylvatica was selected because it is among the major commercial species in the area.

In order to create a sample for our research the method of simple random sampling was used. By using $\mathrm{R}$ language a program was created to produce randomly pairs of numbers representing easting and northing, i.e. points in the forest. $\mathrm{R}$ was chosen because has a number of advantages comparing to other languages. $\mathrm{R}$ is free to install, use, update, clone modify or redistribute. $\mathrm{R}$ seems to be growing rapidly in popularity among general users. $\mathrm{R}$ can handle complex and large data, has awesome power, dazzling flexibility and is well supported.

The nearest trees of Fagus sylvatica were measured (Figure 1) at points having the coordinates the program produced. In each three measurements were taken along the stem. At height of 0.3 meters and 1.3 meters the measurements were taken by using caliper while measurements at higher points on the stem were taken using relascop. Measures of the diameter over-bark were taken along the stem at the $0.1,0.3,0.5,0.7$, and 0.9 of the total height and at 3.3, 5.3, 7.3, etc meters till the high where the distance between the top and the last measurement is shorter than 2 meters.

In the beginning a pre-sample of 66 randomly selected trees were measured. The mean taper $(\mathrm{cm} / \mathrm{m})$ was calculated using Equation 1, that Anuchin (1970) used. To calculate the appropriate sample size of each taper, the following equation was used (Levy \& Lemeshow, 1991):

$$
n=\frac{t^{2} c v^{2}}{d^{2}}
$$

where $n$ is the sample size of each taper, $t$ is the value of student's distribution ( $t$-distribution) for probability $95 \%, c v$ is the coefficient of variance, and $d$ is the maximum acceptable error expressed as a percent of the mean. For practical reasons the maximum acceptable error is $10 \%$.

In this research tapers are divided in three categories (groups). The first category includes five tapers having large end diameter the diameter at 0.3 meters from the ground and small diameter the $0.1,0.3,0.5,0.7$, and 0.9 of the total tree height. The tapers of this category are symbolized as $\alpha_{0.3-0.1 \mathrm{~h}}$, $\alpha_{0.3-0.3 \mathrm{~h}}, \alpha_{0.3-0.5 \mathrm{~h}}, \alpha_{0.3-0.7 \mathrm{~h}}$, and $\alpha_{0.3-0.9 \mathrm{~h}}$, respectively.

The second category includes ten tapers. Four tapers having large diameters at 0.1 of total height and small diameters at $0.3,0.5,0.7$, and 0.9 of total height respectively and are symbolized as $\alpha_{0.1 \mathrm{~h}-0.3 \mathrm{~h}}, \alpha_{0 . \mathrm{hh}-0.5 \mathrm{~h}}, \alpha_{0 . \mathrm{hh}-0.7 \mathrm{~h}}$, and $\alpha_{0 . \mathrm{hh}-0.9 \mathrm{~h}}$, three tapers having large diameters at 0.3 of total height and small diameters at $0.5,0.7$, and 0.9 of total height are symbolized as $\alpha_{0.3 \mathrm{~h}-0.5 \mathrm{~h}}, \alpha_{0.3 \mathrm{~h}-0.7 \mathrm{~h}}$, and $\alpha_{0.3 \mathrm{~h}-0.9 \mathrm{~h}}$, two tapers having large diameters at 0.5 of total height and small diameters at 0.7 and 0.9 of total height are symbolized as $\alpha_{0.5 \mathrm{~h}-0.7 \mathrm{~h}}$, and $\alpha_{0.5 \mathrm{~h}-0.9 \mathrm{~h}}$, and one taper having large diameter at 0.7 of total height and small diameter at 0.9 of total height is symbolized as $\alpha_{0.7 \mathrm{~h}-0.9 \mathrm{~h}}$. 


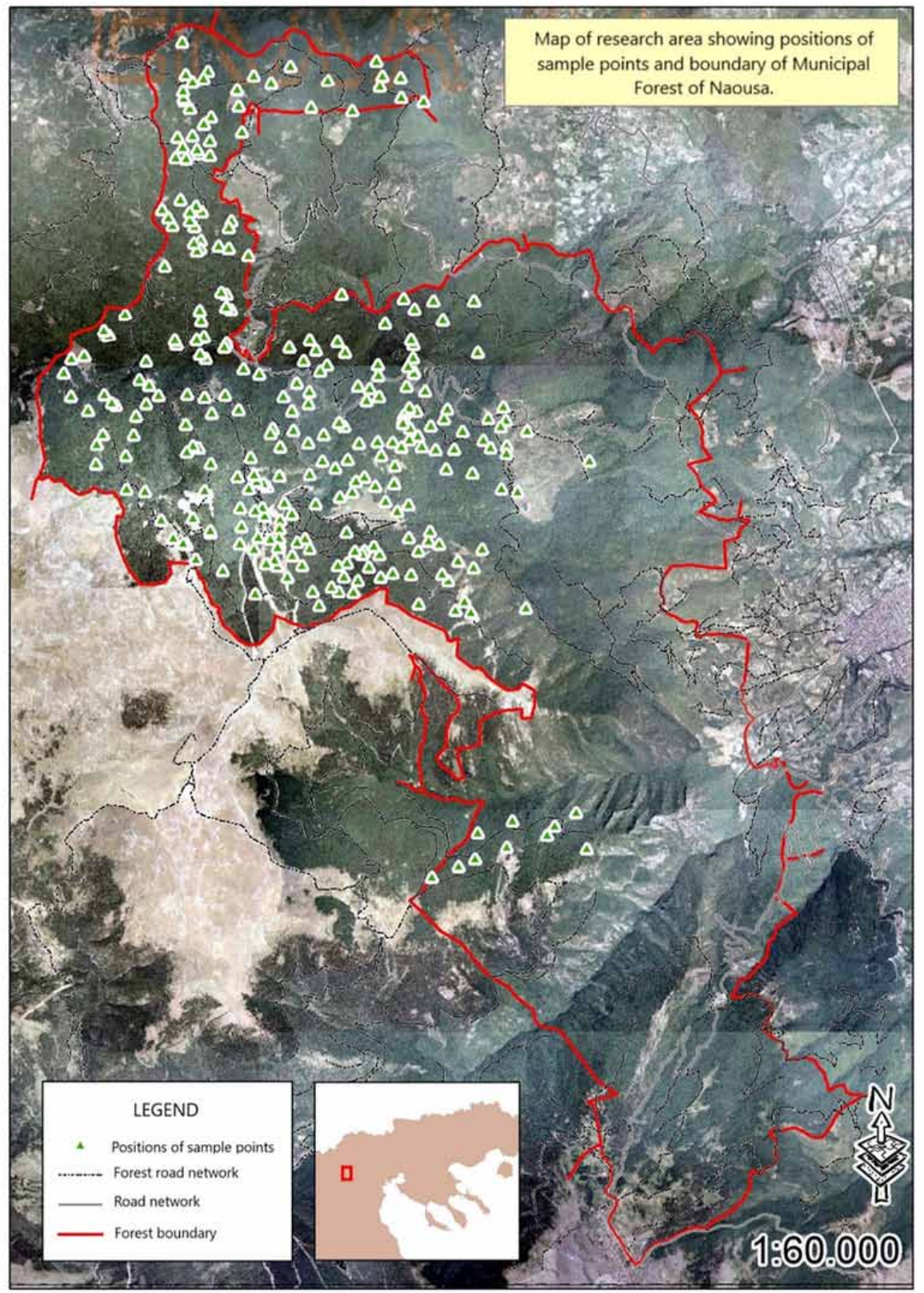

The third category includes seventy-eight tapers. All tapers of this category derived from diameters measured at absolute heights on the stem of each tree from the ground. For example, a taper starts from 0.3 meters to $1.3,3.3,5.3$, and so on up to 23.3 meters with the symbolism of $\alpha_{0,3-1,3}, \alpha_{0,3-3,3}$ and so on. Other tapers are starting from 1.3, 3.3, 5.3 and every two meters up to 23.3 meters. As the height of the large diameter or small diameter of a taper is getting larger, the size of the sample of trees entering that calculation is reduced. 
After finishing the collection of data, the statistical package SPSS ver. 22 was used to analyze them. During the analysis procedure the existence of the outliers and extreme values was examined. Calculation of the mean, the standard error of the mean, the upper and lower bound of $95 \%$ confidence interval for the mean, the 5\% trimmed mean, the median, the coefficient of variance, the minimum and maximum values, the range, the interquartile range, the skewness, and the kurtosis took place. Because skewness and kurtosis statistics are sensitive to anomalies in the distribution were studied in conjunction with a histogram and boxplot. In order to have a visual check, not an air-tight proof, if the values of a taper are following or not the normal distribution, the $\mathrm{Q}-\mathrm{Q}$ plots where used. By the end of the statistical analysis, a conclusion that taper fits or not the Normal distribution can be extracted.

In order to see which distribution each taper fits, a program in $\mathrm{R}$ was created. The program uses the package "fitdistrplus". The "fitdistrplus", created by Delignette-Muller et al. (2015) and DelignetteMuller and Dutang (2015), and provides functions for fitting univariate distributions to different types of data and also provides various functions to compare the fit of several distributions to the same data set and can handle to bootstrap parameter estimates. Data were tested if they fit Lognormal distribution, Gamma distribution, and Weibull distribution. The parameters of the distribution were estimated by the maximum likelihood function. The goodness of fit to the distributions was evaluated using Kolmogorov- Smirnov (KS), Cramer-von Mises (CvM), and Anderson-Darling (AD). Aikake's Information Criterion (Akaike, 1973) and Bayesian Information Criterion (BIC) (Schwarz, 1978) were also evaluated. The smallest value to the test shows the distribution that fits to the data. Aikake's Information Criterion (Akaike, 1973) and Bayesian Information Criterion (BIC) are two widely accepted goodness of fit criteria for comparing non-nested models as they essentially represent a penalized likelihood criteria. (Li \& Weiskittel, 2010).

\section{RESULTS AND DISCUSSION}

Sample size for each taper was calculated by using equation 7. The value of parameter $t$ for all tapers is equal to 1.96, and the maximum acceptable error for all tapers is $10 \%$. So, the taper with the higher coefficient of variance will have the largest sample. Taper $\alpha_{7.3-9.3}$ has the larger coefficient of variance and results a sample of 276 trees. In order to have all tapers an appropriate accuracy of the estimates, 300 trees by random sampling were measured. Up to the height of 9.3 meters 300 tree stems were measured. In the height of 11.3 meters 296 tree stems were measured, in 13.3 meters 285 tree stems were measured, in 15.3 meters 260 tree stems were measured, in 17.3 meters 212 tree stems were measured, in 19.3 meters 163 tree stems were measured, in 21.3 meters 104 tree stems were measured, in 23.3 meters 46 tree stems were measured, and in 25.3 meters 12 tree stems were measured. The average height of the trees is 19,53 meters. Data analysis results showed that the minimum diameter of sample trees is 12.3 centimeters, the maximum diameter of sample trees is 52.1 centimeters, the minimum total height of the sample trees is 10.1 meters and the maximum total height is 29 meters.

Figure 2 shows boxplot for tapers of the first category and it can be seen that, all the examined tapers have outliers ("x") but no extremes values (“+”). The outlier values come from open grown trees or from trees with good growth and are not removed from the dataset. The outlier values are not from the same trees for all tapers.

The results of descriptive statistics of the first group of tapers are showed in Table 1 and it can be seen that the taper $\alpha_{0.3-0.1 \mathrm{~h}}$ has the largest mean, almost the double of the $\alpha_{0.3-0.3 \mathrm{~h}}$ because of root swelling. The mean decreases as the height of the small diameter of the tapes increases till the taper $\alpha_{0.3-0.7}$ and then an increase is observed. The point at which the reduction of the mean of the tapers is stopped is not constant but is influenced by the height at which the crown of the tree beggins. Philip (1994) reports that taper values are large when referring to portions of the trunk influenced by the root swelling and the presence of crown.

Comparing the mean values of each taper by the corresponding $5 \%$ trimmed mean it is evident that the 5\% lower and higher values do not affect the mean. The coefficient of variance shows that 


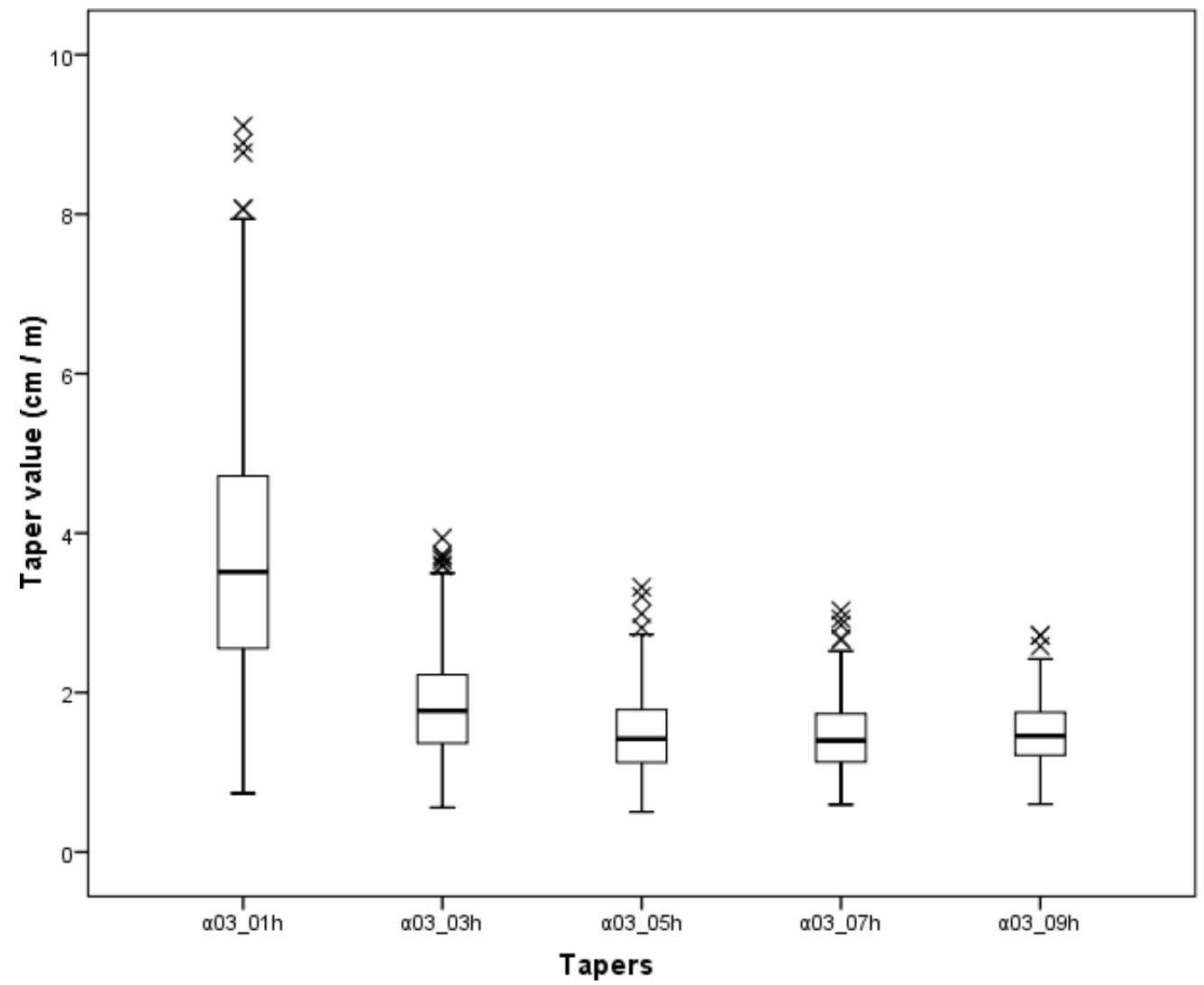

Table 1. Descriptive statistics for the first category of tapers

\begin{tabular}{|l|l|l|l|l|l|}
\hline \multicolumn{1}{|c|}{ Statistic } & \multicolumn{1}{c|}{$\boldsymbol{\alpha}_{\text {0.3-0.1h }}$} & \multicolumn{1}{c|}{$\boldsymbol{\alpha}_{\mathbf{0 . 3 - 0 . 3 h}}$} & \multicolumn{1}{c|}{$\boldsymbol{\alpha}_{\mathbf{0 . 3 - 0 . 5 h}}$} & \multicolumn{1}{c|}{$\boldsymbol{\alpha}_{\mathbf{0 . 3 - 0 . 7 h}}$} & \multicolumn{1}{c|}{$\boldsymbol{\alpha}_{\text {0.3-0.9h }}$} \\
\hline Mean & 3.7137 & 1.8487 & 1.5027 & 1.4638 & 1.5022 \\
\hline 5\% Trimmed Mean & 3.6372 & 1.8223 & 1.4774 & 1.4431 & 1.4918 \\
\hline Median & 3.5115 & 1.7703 & 1.4206 & 1.3995 & 1.4557 \\
\hline Coefficient of variance & $43.55 \%$ & $35.66 \%$ & $32.54 \%$ & $29.77 \%$ & $26.15 \%$ \\
\hline Std. Deviation & 1.6176 & 0.6590 & 0.4891 & 0.4358 & 0.3929 \\
\hline Minimum value & 0.7352 & 0.5568 & 0.5045 & 0.5937 & 0.5997 \\
\hline Maximum value & 9.1069 & 3.9394 & 3.3213 & 3.0278 & 2.7163 \\
\hline Skewness & 0.6934 & 0.6152 & 0.7950 & 0.7290 & 0.4257 \\
\hline Kurtosis & 0.4079 & 0.1948 & 0.6542 & 0.5842 & 0.0042 \\
\hline
\end{tabular}

the taper $\alpha_{0.3-0.9 \mathrm{~h}}$ has less variability than the other tapers of the group. Comparing the value of the mean with the corresponding value of the median in all cases the values of the median are a bit lower than the values of the mean. As the distance between the two measured diameters of a taper is getting larger, the values of standard deviation, the range, the minimum, and the maximum values and the interquartile range are getting smaller. By examining the skewness and kurtosis of the tapers 
the conclusion is that the distribution of the taper $\alpha_{0.3-0.9 \mathrm{~h}}$ is fairly symmetric and it can be said that fits to the Normal distribution.

In the next step of the analysis, frequency histograms for each taper were examined and the distributions were also found fairly symmetric. However, histograms could be misleading since the look of a histogram is largely dependent on the "bin" size; the space between the tick marks. By using Q-Q plots it can be seen if the data fits to the Normal distribution or not. Viewing in Figure 3 the Q-Q plots, it can be said that all the tapers approach fairly the Normal distribution. In the extremes of the lower left and upper right the points, representing taper values, fall a little bit of the line; in a Q-Q plot that is not uncommon. Those few points of the line are not enough to say that the distribution of the data is not Normal. However, this is a visual check, not an air-tight proof, so it is somewhat subjective.

For that reason, the examination of data using strictly statistical tools is the next step of the analysis. A Kolmogorov-Smirnov statistical test is taking place and shows that only taper $\alpha_{0.3-0.9 \mathrm{~h}}$ fits to the Normal distribution. For the other tapers by using the "fitdistrplus" package, the results show that taper $\alpha_{0.3-0.1 \mathrm{~h}}$ and $\alpha_{0.3-0.3 \mathrm{~h}}$ fits to Gamma distribution while $\alpha_{0.3-0.5 \mathrm{~h}}$ and $\alpha_{0.3-0.7 \mathrm{~h}}$ fit to Lognormal distribution.

For the second category of tapers the boxplots are presented in Figure 4. All tapers have outliers ("x") and extreme values ("+"), in conjunction to the first group tapers where there are no extreme values.

Extreme values can occur because of faulty adjustments of the measurement instruments or by not applying appropriately the correct methodological measurement process. In our cases the extreme values come, mainly, from open grown trees and outliers are coming from good growth trees. The taper values are ranging from $1.03 \mathrm{~cm} / \mathrm{m}$ to $1.63 \mathrm{~cm} / \mathrm{m}$ when the taper values of the first group are ranging from $1.46 \mathrm{~cm} / \mathrm{m}$ to $3.71 \mathrm{~cm} / \mathrm{m}$. In taper $\alpha_{0.5 \mathrm{~h}-0.9 \mathrm{~h}}$ an outlier from the bottom side exists. This taper comes from a very cylindrical stem. The median in many cases is not in the middle of the rectangular box. In Table 2 the descriptive statistics of tapers are presented. In all tapers the difference between the mean and the 5\% trimmed mean is small, less than $4 \%$. The coefficient of variance ranges from $27.39 \%$ for taper $\alpha_{0.1 \mathrm{~h}-0.9 \mathrm{~h}}$ to $49 \%$ for taper $\alpha_{0.3 \mathrm{~h}-0.5 \mathrm{~h}}$. It is accepted that large values of the CV coefficient make the mean value a "bad" index of central tendency. Taper $\alpha_{0.3 \mathrm{~h}-0.5 \mathrm{~h}}$ has the largest value of kurtosis and skewness. Small values of skewness and kurtosis are observed for the tapers $\alpha_{0.5 \mathrm{~h}-0.9 \mathrm{~h}}, \alpha_{0.3 \mathrm{~h}-0.9 \mathrm{~h}}$, and $\alpha_{0.1 \mathrm{~h}-0.9 \mathrm{~h}}$.

By examining the histograms, the Q-Q plots, the boxplots, and the descriptive statistics of tapers $\alpha_{0.5 h-0.9 h}, \alpha_{0.3 h-0.9 h}$, and $\alpha_{0.1 h-0.9 h}$ it seems that the distributions of these tapers are fairly symmetric and it can be said that these tapers fit to the Normal distribution (Figure 5). Since there is no conclusion about which distribution fits to other seven tapers, the use of "fitdistrplus" package took place. By performing the fitting, results showed that tapers $\alpha_{0.1 h-0.3 h}, \alpha_{0.1 h-0.5 h}, \alpha_{0.1 h-0.7 h}, \alpha_{0.3 h-0.5 h}$, and $\alpha_{0.3 h-0.7 h}$ fit to the Lognormal distribution while $\alpha_{0.5 \mathrm{~h}-0.7 \mathrm{~h}}$, and $\alpha_{0.7 \mathrm{~h}-0.9 \mathrm{~h}}$ fit to the Gamma distribution (Table 3).

Analysis procedure for tapers of the third category focus only to examine if the data fit or not to normal distribution and did not examined if they fit to Gamma, Lognormal or Weibull distribution.

Considering the descriptive statistics of the tapers of the third category, taper $\alpha_{0.3-1.3}$ has the highest value of the mean, $(5,39 \mathrm{~cm}$ per current meter), as it is the one most affected by the root swelling. All other tapers show significantly lower values. For tapers whose large diameter is located on the lower part of the tree (from $0.3 \mathrm{~m}$ to $3.3 \mathrm{~m}$ ), i.e. the tapers $\alpha_{0.3-1.3}, \alpha_{0.3-3.3}, \alpha_{0.3-5.3,} \alpha_{0.3-7.3,}, \alpha_{0.3-9.3,}, \alpha_{0.3-11.3,} \alpha_{0.3-13.3 \ldots}$ $\alpha_{0.3-23.3,}$ and $\alpha_{0.3-1.3}, \alpha_{1.3-3.3}, \alpha_{1.3-5.3,} \alpha_{1.3-7.3,} \alpha_{1.3-9.3,} \alpha_{1.3-11.3,} \alpha_{1.3-13.3} \alpha_{1.3-23.3}$ their arithmetic mean start from a value then decrease and then start to rise again slow. All other taper means from the initial value increase continuously because they refer to segments not affected by the root swelling.

Of the seventy eight tapers five of them $\left(\alpha_{3,3-5,3,}, \alpha_{3,3-7,3,}, \alpha_{3,3-9,3,3}, \alpha_{5,3-7,3,}, \alpha_{5,3-9,3,3}\right)$ have values less than one centimeter per meter, thirty nine have values from $1 \mathrm{~cm} / \mathrm{m}$ to $1,43 \mathrm{~cm} / \mathrm{m}$, thirty one have values from 1,43 to $1,89 \mathrm{~cm} / \mathrm{m}$ and three have values greater than $1,89 \mathrm{~cm}$ per meter. 
International Journal of Agricultural and Environmental Information Systems

Volume 10 • Issue 1 • January-March 2019

Figure 3. Q - Q plots of tapers $\alpha_{0.3-0.1 \mathrm{~h},} \alpha_{0.3-0.3 \mathrm{~h}} \alpha_{0.3-0.5 \mathrm{~h}}, \alpha_{0.3-0.7 \mathrm{~h}}$ and $\alpha_{0.3-0.9 \mathrm{~h}}$

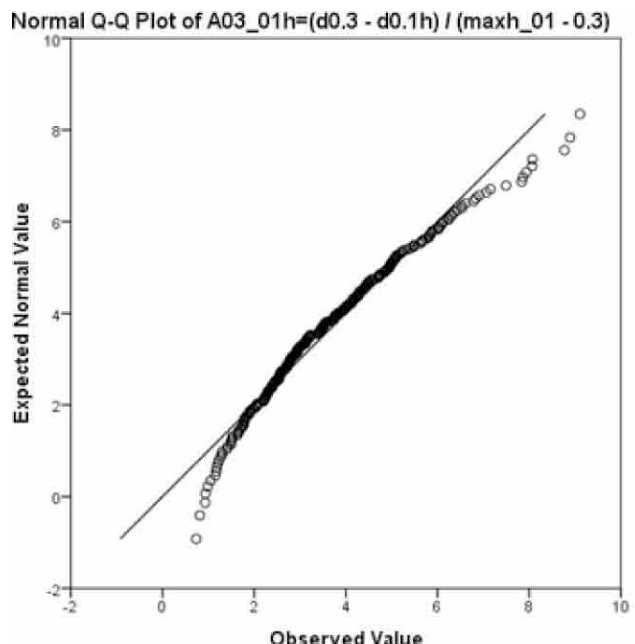

Normal Q-Q Plot of A03_03h=(d0.3 - d0.3h) I (maxh_03 - 0.3)
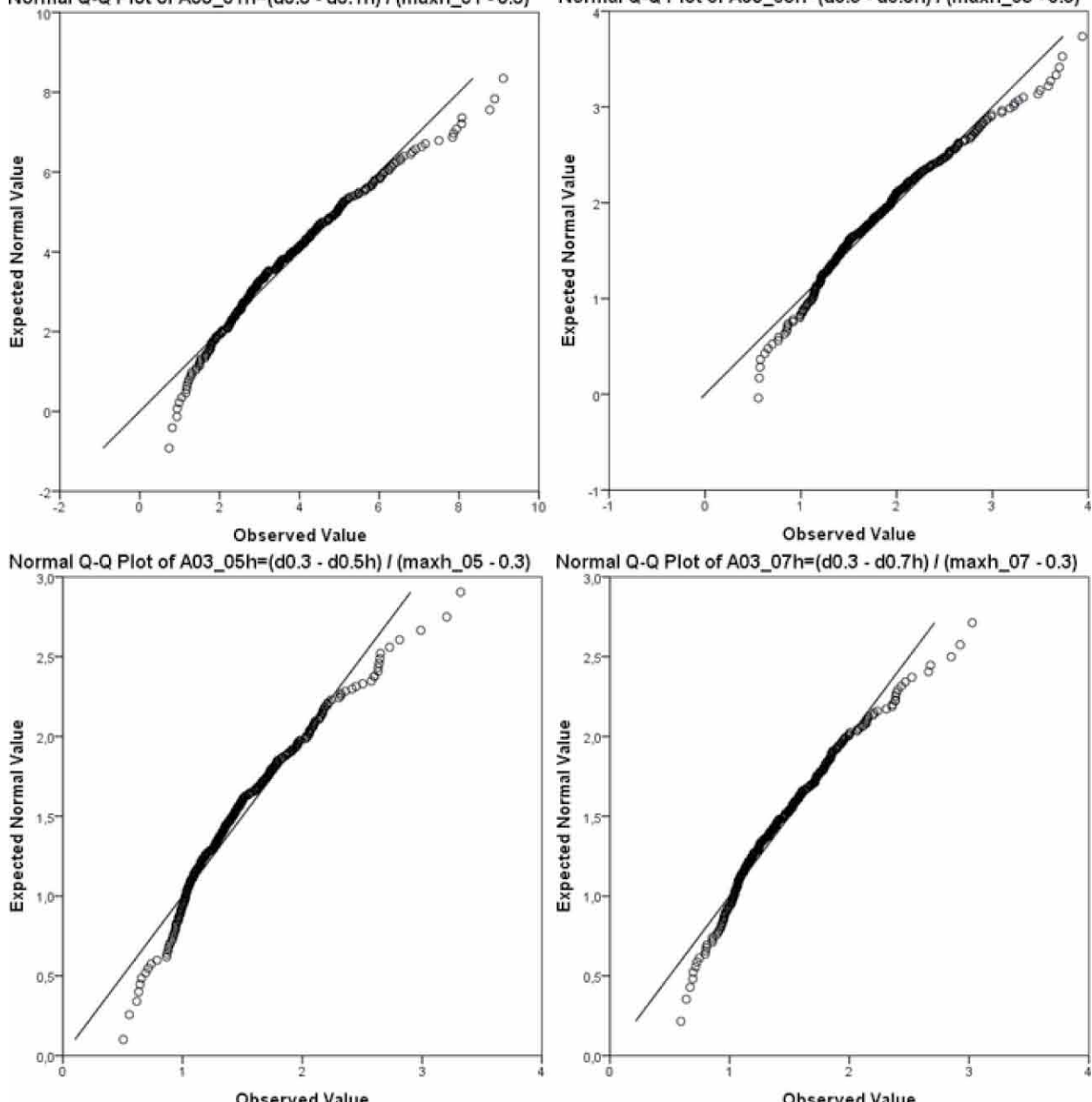

Normal Q-Q Plot of A03_07h $=(\mathrm{d} 0.3 \cdot \mathrm{d} 0.7 \mathrm{~h}) /\left(\operatorname{maxh} \_07-0.3\right)$

erved Value

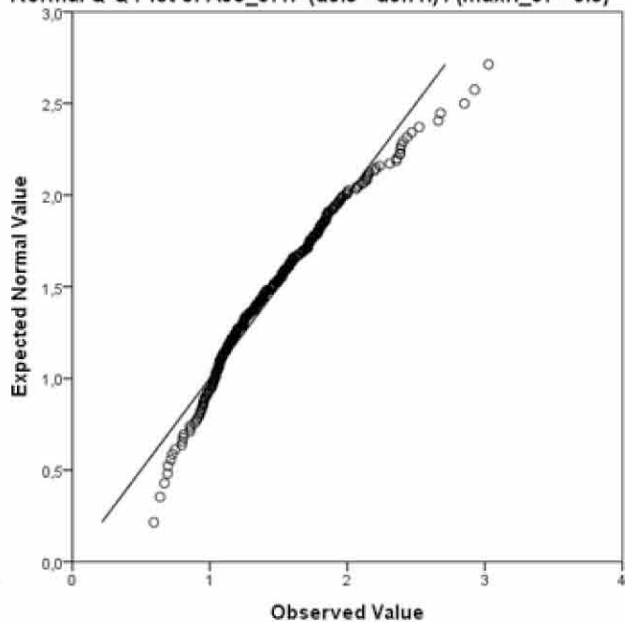

Normal Q-Q Plot of A03_09h=(d0.3 - d0.9h) / (maxh_09 - 0.3)

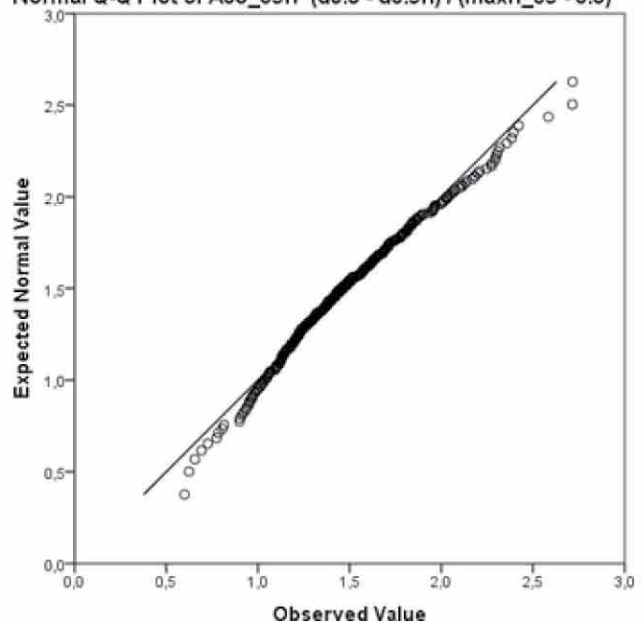




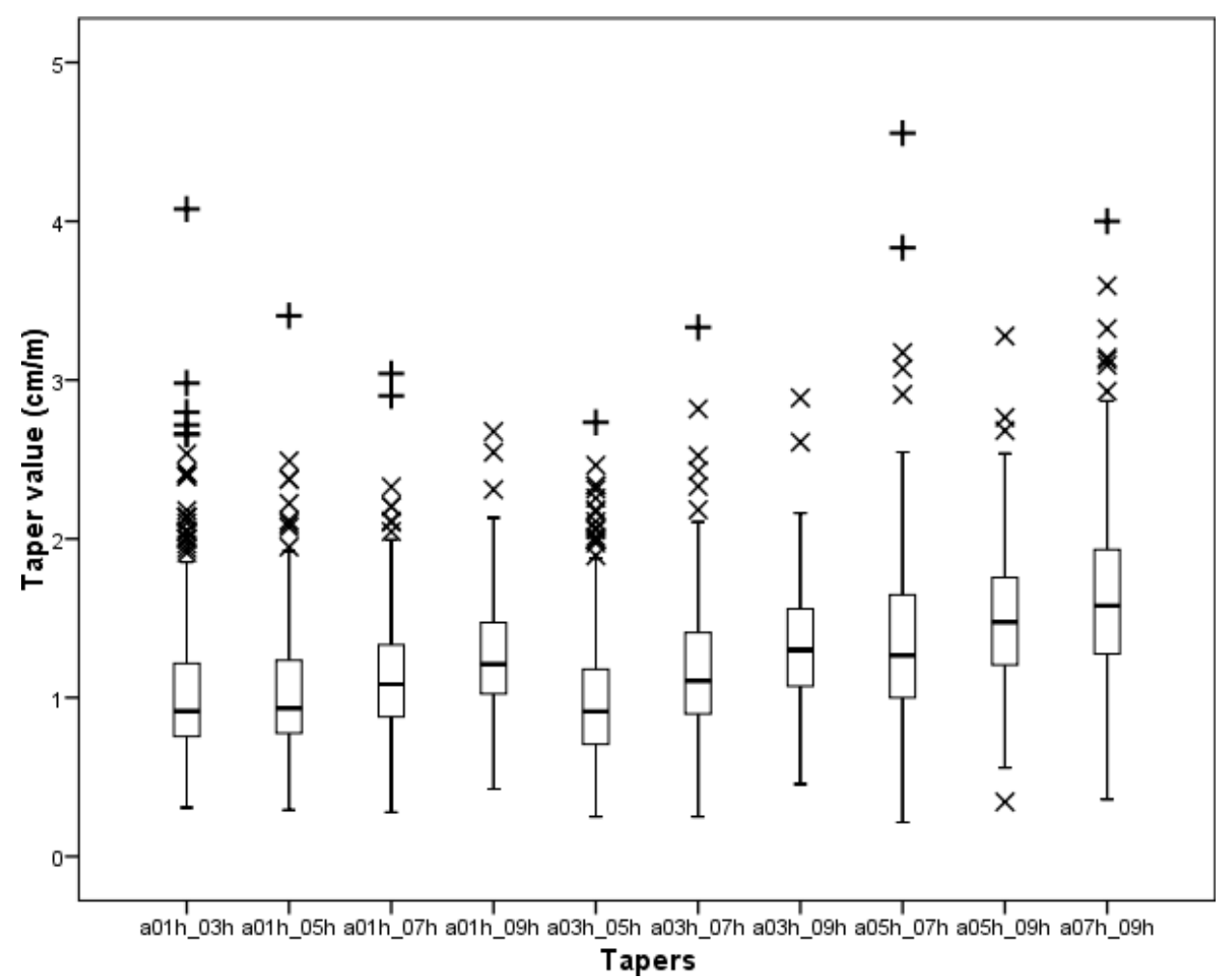

Comparing the mean of a taper with the $5 \%$ trimmed mean of the same taper the difference is ranging from $0 \%$ to $3 \%$ for all the tapers of third category.

About the median, the taper $\alpha_{0.3-1.3}$ has the biggest value $(5,05 \mathrm{~cm} / \mathrm{m})$ because of root swelling. Taper $\alpha_{5.3-7.3}$ has the smallest value $(0,75 \mathrm{~cm} / \mathrm{m})$ because is not affected neither by root swelling or the branches of the crown. By examining the values we can conclude that lower segments of the trunk i.e. up to 7.3 meters have the biggest median values following by the upper segments of the trunk i.e. above 17,3 meters. Middle segments of the trunk have the lowest median values.

Minimum values of tapers of third category are ranging from $0.01 \mathrm{~cm} / \mathrm{m}$ to $1 \mathrm{~cm} / \mathrm{m}$. Minimum values are observed in tapers where the large and small diameter are 2 meters away, for example $\alpha_{3.3-5.3,}$ $\alpha_{11.3-13.3}, \alpha_{13.3-15.3}, \alpha_{15.3-17.3}$ and $\alpha_{17.3-19.3}$. Relating the minimum values of the taper with the corresponding segment of the trunk that taper indicates, shows that tapers which have large diameter up to 7.3 meters, have values initially decrease and after height of 13.3 meters their values are increasing. On the contrary tapers whose large diameter is from 9.3 meters and higher show upward trends throughout the length of the trunk.

Maximum values of tapers are ranging for $2.28 \mathrm{~cm} / \mathrm{m}$ for $\alpha_{17.3-23.3}$ to 15.1 for taper $\alpha_{0.3-1.3}$.

Range values for the tapers of that category are from 1.31 up to 14.2. For taperw having same large diameter range values are getting smaller as the distance between the diameters of the taper is getting longer.

Taper $\alpha_{5.3-7.3}$ has the biggest coefficient of variance $(67,48 \%)$ of all tapers in contrast with tapers $\alpha_{0.3-23.3}$, and $\alpha_{17.3-23.3}$ which have the smallest coefficient of variance $21,1 \%$.

Standard deviation decreases as the distance between the two diameters of a taper is getting bigger. Tapers $\alpha_{1.3-21.3}, \alpha_{1.3-19.3}$ are having the lowest values (0.29) of standard deviation while tapers $\alpha_{0.3-1.3}$, $\alpha_{0.3-3.3}, \alpha_{11.3-13.3}$ are having the highest values of standard deviation, 2.66, 1.02, and 0.83 respectively. 
Table 2. Descriptive statistics for the second category of tapers

\begin{tabular}{|c|c|c|c|c|c|c|}
\hline Statistic & $\alpha_{0.1 \mathrm{~h}-0.3 \mathrm{~h}}$ & $\alpha_{0.1 \mathrm{~h}-0.5 \mathrm{~h}}$ & $\alpha_{0.1 \mathrm{~h}-0.7 \mathrm{~h}}$ & $\alpha_{0.1 \mathrm{~h}-0.9 \mathrm{~h}}$ & $\alpha_{0.3 \mathrm{~h}-0.5 \mathrm{~h}}$ & $\alpha_{0.3 \mathrm{~h}-0.7 \mathrm{~h}}$ \\
\hline Mean & 1.0626 & 1.0370 & 1.1480 & 1.2694 & 1.0114 & 1.1907 \\
\hline 5\% Trimmed Mean & 1.0150 & 1.0017 & 1.1210 & 1.2550 & .9704 & 1.1625 \\
\hline Median & 0.9212 & 0.9370 & 1.0843 & 1.2138 & .9135 & 1.1061 \\
\hline Coefficient of variance & $48.78 \%$ & $40.97 \%$ & $34.14 \%$ & $27.39 \%$ & $49.02 \%$ & $37.31 \%$ \\
\hline Std. Deviation & 0.5184 & 0.4249 & 0.3920 & 0.3477 & 0.4958 & 0.4443 \\
\hline Minimum value & 0.3075 & 0.2918 & 0.2779 & 0.4252 & 0.2500 & 0.2500 \\
\hline Maximum value & 4.0770 & 3.4052 & 3.0409 & 2.6755 & 4.7937 & 3.3645 \\
\hline Skewness & 1.8019 & 1.8339 & 1.3715 & 0.7784 & 2.2556 & 1.3253 \\
\hline Kurtosis & 4.8477 & 5.9402 & 3.5247 & 1.2410 & 11.2418 & 3.4577 \\
\hline & $\alpha_{0.3 \mathrm{~h}-0.9 \mathrm{~h}}$ & \multicolumn{2}{|c|}{$\alpha_{0.5 \mathrm{~h}-0.7 \mathrm{~h}}$} & \multicolumn{2}{|c|}{$\alpha_{0.5 \mathrm{~h}-0.9 \mathrm{~h}}$} & $\alpha_{0.7 \mathrm{~h}-0.9 \mathrm{~h}}$ \\
\hline Mean & 1.3383 & \multicolumn{2}{|l|}{1.3701} & \multicolumn{2}{|l|}{1.5018} & 1.6335 \\
\hline 5\% Trimmed Mean & 1.3279 & \multicolumn{2}{|l|}{1.3409} & \multicolumn{2}{|l|}{1.4925} & 1.6115 \\
\hline Median & 1.3009 & \multicolumn{2}{|l|}{1.2679} & \multicolumn{2}{|l|}{1.4765} & 1.5783 \\
\hline Coefficient of variance & $27.87 \%$ & \multicolumn{2}{|l|}{$40.51 \%$} & \multicolumn{2}{|l|}{$28.65 \%$} & $33.57 \%$ \\
\hline Std. Deviation & 0.3730 & \multicolumn{2}{|l|}{0.5550} & \multicolumn{2}{|l|}{0.4303} & 0.5485 \\
\hline Minimum value & 0.4557 & \multicolumn{2}{|l|}{0.2143} & \multicolumn{2}{|l|}{0.3429} & 0.3590 \\
\hline Maximum value & 2.8878 & \multicolumn{2}{|l|}{4.5547} & \multicolumn{2}{|l|}{3.2774} & 4.0000 \\
\hline Skewness & 0.6616 & \multicolumn{2}{|l|}{1.3169} & \multicolumn{2}{|l|}{0.4119} & 0.7402 \\
\hline Kurtosis & 1.0401 & \multicolumn{2}{|l|}{4.3551} & \multicolumn{2}{|l|}{0.6561} & 1.4890 \\
\hline
\end{tabular}

Table 3. AIC values for tapers of the second group

\begin{tabular}{|l|l|l|l|l|}
\hline \multicolumn{1}{|c|}{ AIC Values } & \multicolumn{1}{c|}{ Weibull } & \multicolumn{1}{c|}{ Gamma } & \multicolumn{1}{c|}{ Lognormal } & \multicolumn{1}{c|}{ Normal } \\
\hline Taper $\alpha_{0.1 h-0.3 h}$ & 407,6738 & 355,1488 & $\mathbf{3 3 3 , 0 7 3 0}$ & 460,1480 \\
\hline Taper $\alpha_{0.1 h-0.5 h}$ & 318,1139 & 255,6504 & $\mathbf{2 3 8 , 1 2 4 6}$ & 340,7512 \\
\hline Taper $\alpha_{0.1 h-0.7 h}$ & 293,9783 & 237,6054 & $\mathbf{2 2 8 , 9 3 2 1}$ & 292,46 \\
\hline Taper $\alpha_{0.1 h-0.9 h}$ & 236,0383 & 197,0024 & 197,6496 & $\mathbf{1 9 2 , 5 0}$ \\
\hline Taper $\alpha_{0.3 h-0.5 h}$ & 380,9053 & 328,6538 & $\mathbf{3 1 2 , 0 9 3 8}$ & 433,4112 \\
\hline Taper $\alpha_{0.3 h-0.5 h}$ & 359,0191 & 313,7427 & $\mathbf{3 0 9 , 9 5 7 7}$ & 367,5955 \\
\hline Taper $\alpha_{0.3 h-0.9 h}$ & 275,0364 & 244,8722 & 248,9141 & $\mathbf{2 4 2 , 6 8 9 8}$ \\
\hline Taper $\alpha_{0.5 h-0.7 h}$ & 486,0048 & $\mathbf{4 5 7 , 1 4 3 3}$ & 468,4496 & 501,12 \\
\hline Taper $\alpha_{0.5 h-0.9 h}$ & 355,8444 & 350,5943 & 361,7957 & $\mathbf{3 4 8 , 4 1 9 7}$ \\
\hline Taper $\alpha_{0.7 h-0.9 h}$ & 495,8682 & $\mathbf{4 7 8 , 5 8 3 0}$ & 493,6704 & 494,06 \\
\hline
\end{tabular}

It is noted that low standard deviation values are observed in tapers whose measured diameters are having long distances between them.

The skewness of all tapers is positive. The data distribution of taper $\alpha_{1.3-3.3}$ shows light asymmetry, its skewness is the lowest of all and is equal to 1,07 while taper $\alpha_{5.3-9.3}$ has the biggest value of skewness equal to 16.27 . 
Figure 5. $Q-Q$ plots of tapers $\alpha_{0.1 \mathrm{~h}-0.9 \mathrm{~h}}, \alpha_{0.3 \mathrm{~h}-0.9 \mathrm{~h}}$, and $\alpha_{0.5 \mathrm{~h}-0.9 \mathrm{~h}}$
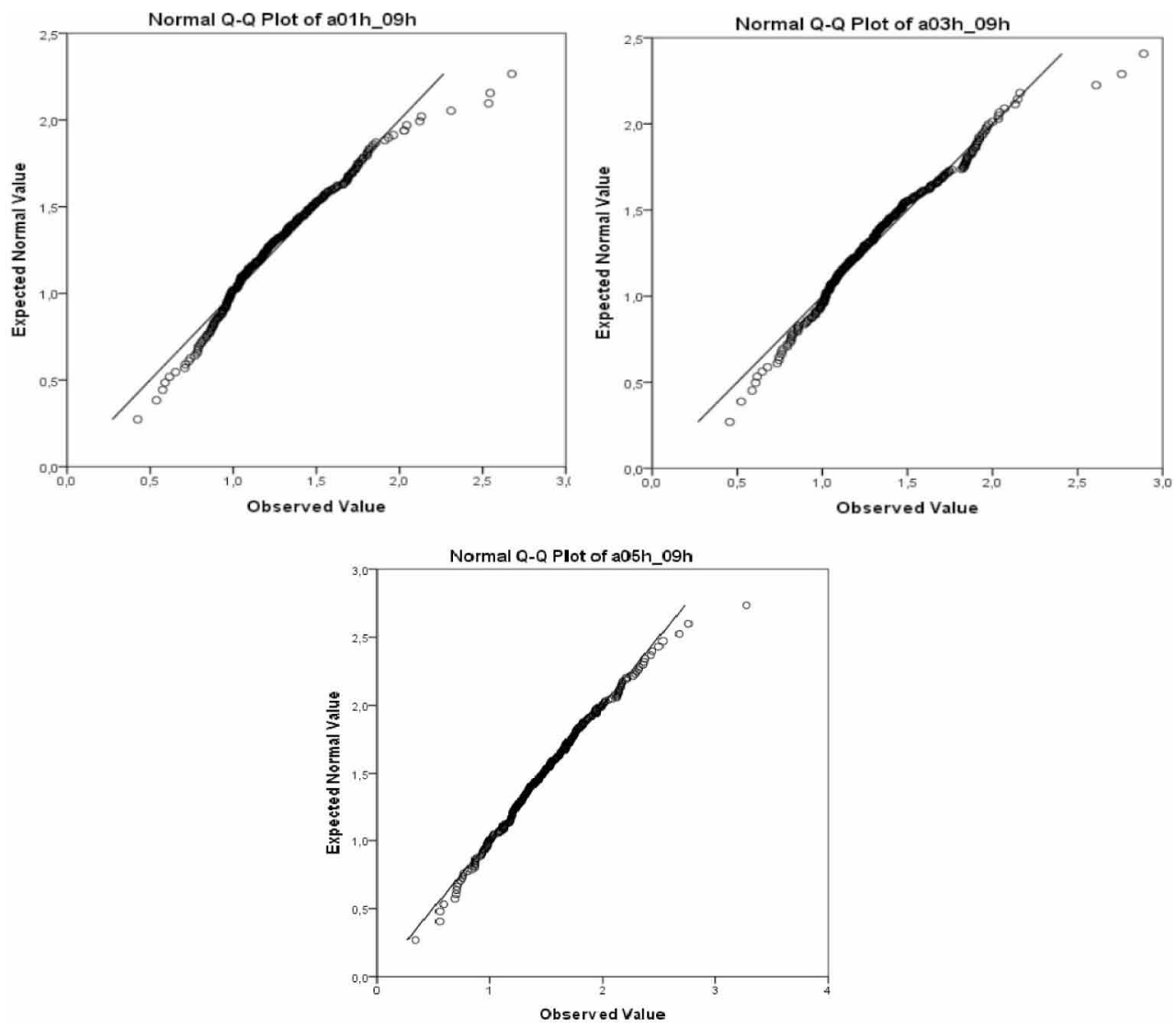

Most of the tapers are having positive Kurtosis values (leptokurtic distribution) with values ranging from -0.64 for taper $\alpha_{17.3-23.3}$ to 14.45 for taper $\alpha_{3.3-7.3}$. From 78 tapers 60 have values from 0 to 4.8. Tapers $\alpha_{0.3-3.3}, \alpha_{0.3-5.3}, \alpha_{17.3-21.3}$ and $\alpha_{21.3-23.3}$ are having platykurtic distributions.

Analysis of tapers boxplots results that, with exception of tapers $\alpha_{0.3-3.3}, \alpha_{0.3-5.3}$, and $\alpha_{17.3-23.3}$, all other tapers have outliers or/and extreme values. Outliers and extreme values are coming for open growth trees and old trees.

Final step of the analysis was the use of histograms and Q-Q plots to see, by visual check, which tapers are following normal distribution. Table 4 shows the results.

It can be seen that tapers having large diameters at 0.3 meters are fit to normal distribution according to visual check.

By using the $\mathrm{R}$ program to examine, with strictly statistical rules, the distribution of the data, it has been found that data of the tapers $\alpha_{0.3-19.3}, \alpha_{0.3-21.3}, \alpha_{0.3-23.3}, \alpha_{1.3-21.3}, \alpha_{1.3-23.3}, \alpha_{11.3-21.3}$ and $\alpha_{13.3-21.3}$ fit to normal distribution.

\section{CONCLUSION}

The examination of first and second group tapers of Fagus sylvatica shows that all examined tapers have values greater than $1 \mathrm{~cm} / \mathrm{m}$. Trees with a high degree of taper (greater than $1 \mathrm{~cm} / \mathrm{m}$ ) are said to have poor form, while those with low degree of taper (less than $1 \mathrm{~cm} / \mathrm{m}$ ) have good form. From practical view, the taper whose large diameter is at 0.3 meters from the ground, is easiest to calculate 
Table 4. Distribution of tapers of third category

\begin{tabular}{|c|c|c|c|c|c|}
\hline Taper & Distribution & Taper & Distribution & Taper & Distribution \\
\hline$\alpha_{0,3-1,3}$ & Normal & $\alpha_{3,3-11,3}$ & Not normal & $\alpha_{9,3-15,3}$ & Not normal \\
\hline$\alpha_{0,3-3,3}$ & Normal & $\alpha_{3,3-13,3}$ & Not normal & $\alpha_{9,3-17,3}$ & Not normal \\
\hline$\alpha_{0,3-5,3}$ & Normal & $\alpha_{3,3-15,3}$ & Not normal & $\alpha_{9,3-19,3}$ & Normal \\
\hline$\alpha_{0,3-7,3}$ & Normal & $\alpha_{3,3-17,3}$ & Not normal & $\alpha_{9,3-21,3}$ & Normal \\
\hline$\alpha_{0,3-9,3}$ & Normal & $\alpha_{3,3-19,3}$ & Normal & $\alpha_{9,3-23,3}$ & Normal \\
\hline$\alpha_{0,3-11,3}$ & Normal & $\alpha_{3,3-21,3}$ & Normal & $\alpha_{11,3-13,3}$ & Not normal \\
\hline$\alpha_{0,3-13,3}$ & Normal & $\alpha_{3,3-23,3}$ & Normal & $\alpha_{11,3-15,3}$ & Not normal \\
\hline$\alpha_{0,3-15,3}$ & Normal & $\alpha_{5,3-7,3}$ & Not normal & $\alpha_{11,3-17,3}$ & Not normal \\
\hline$\alpha_{0,3-17,3}$ & Normal & $\alpha_{5,3-9,3}$ & Not normal & $\alpha_{11,3-19,3}$ & Normal \\
\hline$\alpha_{0,3-19,3}$ & Normal & $\alpha_{5,3-11,3}$ & Not normal & $\alpha_{11,3-21,3}$ & Normal \\
\hline$\alpha_{0,3-21,3}$ & Normal & $\alpha_{5,3-13,3}$ & Not normal & $\alpha_{11,3-23,3}$ & Normal \\
\hline$\alpha_{0,3-23,3}$ & Normal & $\alpha_{5,3-15,3}$ & Not normal & $\alpha_{13,3-15,3}$ & Not normal \\
\hline$\alpha_{1,3-3,3}$ & Not normal & $\alpha_{5,3-17,3}$ & Not normal & $\alpha_{13,3-17,3}$ & Not normal \\
\hline$\alpha_{1,3-5,3}$ & Not normal & $\alpha_{5,3-19,3}$ & Normal & $\alpha_{13,3-19,3}$ & Normal \\
\hline$\alpha_{1,3-7,3}$ & Not normal & $\alpha_{5,3-21,3}$ & Normal & $\alpha_{13,3-21,3}$ & Normal \\
\hline$\alpha_{1,3-9,3}$ & Not normal & $\alpha_{5,3-23,3}$ & Normal & $\alpha_{13,3-23,3}$ & Not normal \\
\hline$\alpha_{1,3-11,3}$ & Not normal & $\alpha_{7,3-9,3}$ & Not normal & $\alpha_{15,3-17,3}$ & Not normal \\
\hline$\alpha_{1,3-13,3}$ & Not normal & $\alpha_{7,3-11,3}$ & Not normal & $\alpha_{15,3-19,3}$ & Not normal \\
\hline$\alpha_{1,3-15,3}$ & Not normal & $\alpha_{7,3-13,3}$ & Not normal & $\alpha_{15,3-21,3}$ & Normal \\
\hline$\alpha_{1,3-17,3}$ & Not normal & $\alpha_{7,3-15,3}$ & Normal & $\alpha_{15,3-23,3}$ & Normal \\
\hline$\alpha_{1,3-19,3}$ & Normal & $\alpha_{7,3-17,3}$ & Normal & $\alpha_{17,3-19,3}$ & Not normal \\
\hline$\alpha_{1,3-21,3}$ & Normal & $\alpha_{7,3-19,3}$ & Normal & $\alpha_{17,3-21,3}$ & Not normal \\
\hline$\alpha_{1,3-23,3}$ & Normal & $\alpha_{7,3-21,3}$ & Normal & $\alpha_{17,3-23,3}$ & Not normal \\
\hline$\alpha_{3,3-5,3}$ & Not normal & $\alpha_{7,3-23,3}$ & Normal & $\alpha_{19,3-21,3}$ & Normal \\
\hline$\alpha_{3,3-7,3}$ & Not normal & $\alpha_{9,3-11,3}$ & Not normal & $\alpha_{19,3-23,3}$ & Not normal \\
\hline$\alpha_{3,3-9,3}$ & Not normal & $\alpha_{9,3-13,3}$ & Not normal & $\alpha_{21,3-23,3}$ & Not normal \\
\hline
\end{tabular}

its value once the large diameter is easy to be measured with calliper and the small diameter will be estimated by using spiegel relaskop. However, the values of stem taper are affected by the root swelling. May be a better choice is taper from 0.8 meters where the influence of root swelling is not big. Having in mind the results of the graphic techniques (boxplots, histograms, Q-Q plots) and descriptive statistics, it is fair enough to say that all tapers of first category follow the Normal distribution, but from strictly statistical view only taper $\alpha_{0.3-0.9 \mathrm{~h}}$ follows the Normal distribution. Taper $\alpha_{0.3-0.9 \mathrm{~h}}$ has the lowest coefficient of variance which means smaller sample size for exporting results comparing to other tapers of the category. Furthermore, this taper takes into account diameters with distance between them almost $90 \%$ of the total length of the tree.

Examination of the second category tapers shows that most taper have values around $1 \mathrm{~cm} / \mathrm{m}$. None of the measured diameters is affected by the root swelling. The tapers $\alpha_{0.1 \mathrm{~h}-0.9 \mathrm{~h}}, \alpha_{0.3 \mathrm{~h}-0.9 \mathrm{~h}}$ and $\alpha_{0.5 \mathrm{~h}-0.9 \mathrm{~h}}$ fit to Normal distribution, tapers $\alpha_{0.1 h-0.3 h}, \alpha_{0.1 h-0.5 h}, \alpha_{0.1 h-0.7 h}, \alpha_{0.3 h-0.5 h}$, and $\alpha_{0.3 h-0.7 h}$ fit to Lognormal 
distribution and tapers $\alpha_{0.5 \mathrm{~h}-0.7 \mathrm{~h}}$ and $\alpha_{0.7 \mathrm{~h}-0.9 \mathrm{~h}}$ fit to Gamma distribution. Tapers of the upper part of the tree fit different distribution of tapers of the other part of a tree.

It should be mentioned that values of tapers of first and second category arise from mesurements of 300 trees, while values of tapers of third category arise from 300 or less trees depending on the height of the small diameter of examined taper.

Examination of the third category tapers it has been found that if a suitability criterion is the little variability then appropriate are the tapers $\alpha_{0.3-23.3}$ and $\alpha_{0.3-21.3}$. In other case, if the suitability criterion is the mean of taper to be near $1 \mathrm{~cm} / \mathrm{m}$ then the most appropriate tapers are $\alpha_{3,3-5,3} \alpha_{3,3-7.3}$ $\alpha_{3.3-9.3}, \alpha_{5.3-7.3}$ and $\alpha_{5.3-9.3}$. From seventy-eight tapers thirty-seven are fairly symmetrical and can be said that they are approaching normal distribution. By using strictly statistical methods only seven tapers fit to normal distribution.

Having in mind the results of the analysis and descriptive statistics a conclusion that taper $\alpha_{0.3-0.9 \mathrm{~h}}$ has the best statistical behaviour is coming out. The taper $\alpha_{0.3-0.9 \mathrm{~h}}$ has the smallest value of $\mathrm{CV}$ and needs smaller sample size than the other fourteen tapers. Also fits to normal distribution and for its calculation takes into account almost the entire length of the trunk.

A next step of the research is to investigate the level of improvement that the incorporation of taper gives to volume equations. 


\section{REFERENCES}

Anuchin, N. P. (1970). Forest Mensuration (2nd ed.). Jerusalem: Israel Program for Scientific Translations.

Assmann, E. (1970). The principles of forest yield study. New York: Pergamon Press.

Brooks, J. R., Jiang, L., \& Ozcelik, R. (2008). Compatible stem volume and taper equations for Brutian pine, Cedar of Lebanon, and Cilicica fir in Turkey. Forest Ecology and Management, 256(1-2), 147-151.doi:10.1016/j.foreco.2008.04.018

Delignette-Muller, M. L., \& Dutang, C. (2015). fitdistrplus: An R Package for Fitting Distributions. Journal of Statistical Software, 64(4), 1-34. doi:10.18637/jss.v064.i04

Delignette-Muller, M.L., Pouillot, R., Denis, J.B., \& Dutang, C. (2015). fitdistplus: Help to fit a parametric distribution to non-censored or censored data. $\mathrm{R}$ package version 1.0-4.

Goodwin, A. (2009). A cubic tree taper model. Australian Forestry, 72(2), 87-98. doi:10.1080/00049158.2009.10676294

Grey, H. R. (1956). The form and taper of forest tree stems. Oxford: Imperial Forest Institute.

Ikonen, V.-P., Kellomaki, S., Vaisanen, H., \& Peltola, H. (2006). Modelling the distribution of diameter growth along the stem in Scots pine. Trees (Berlin), 20(3), 391-402. doi:10.1007/s00468-006-0053-7

Kozak, A. (1988). A variable-exponent taper model. Canadian Journal of Forest Research, 18(11), 1363-1368. doi:10.1139/x88-213

Larsen, D. R. (2017). Simple taper: Taper equations for the field forester. Proceedings of the In 20th Central Hardwood Forest Conference, Columbia, MO, March 28-April 1 (pp. 265-278).

Larson, P.R. (1963). Stem form development of forest trees. Forest Science Monograph, 5.

Levy, P.S., \& Lemeshow, S. (1991). Sampling of population - Methods and applications. Wiley-Interscience.

Li, R., \& Weiskittel, A. R. (2010). Comparison of model form for estimating stem taper and volume in the primary conifer species of the North American Acadian Region. Annals of Forest Science, 67(3), 17p. doi:10.1051/forest/2009109

Maraseni, T. N., Cockfield, G., \& Apan, A. (2007). Estimation of taper rates and volume of smaller sized logs in spotted gum saw timber plantations in Southeast Queensland, Australia. Southern Hemisphere Forestry Journal, 69(3), 169-173. doi:10.2989/SHFJ.2007.69.3.6.356

Muhairwe, C. K., LeMay, V. M., \& Kozak, A. (1993). Effects of adding tree, stand and site variables to Kozak's variable-exponent taper equation. Canadian Journal of Forest Research, 24(2), 252-259. doi:10.1139/x94-037

Philip, M. (1994). Measuring Trees and Forests (2nd ed.). Wallingford: CAB International.

Podlaski, R., \& Zasada, M. (2008). Comparison of selected statistical distributions for modelling the diameter distributions in natural Abies - Fagus forests in the Swietokrzyski National Park (Poland). European Journal of Forest Research, 127(6), 455-463. doi:10.1007/s10342-008-0229-3

Prodan, M. (1965). Holzmesslehre. Frankfurt am Main: J.D. Sauerlaender's Verlag.

Thomson, A. J., \& Barclay, H. J. (1984). Effects of thinning and urea fertilization on the distribution of area increment along the bole of Douglas-fir at Shawnigan Lake, British Columbia. Canadian Journal of Forest Research, 14(6), 879-884. doi:10.1139/x84-157

Van Laar, A., \& Akça, A. (2007). Forest Mensuration. Springer publications. doi:10.1007/978-1-4020-5991-9

West, P. W. (2009). Tree and forest measurement (2nd ed.). Germany: Springer-Verlag Berlin Heidelberg. doi:10.1007/978-3-540-95966-3 